\title{
Agromyces laixinhei sp. nov. isolated from bat feces in China ${ }^{\S}$
}

\author{
Yanpeng Cheng ${ }^{1,2}$, Yibo Bai ${ }^{1,2}$, Yuyuan Huang ${ }^{2}$, \\ Jing Yang ${ }^{2,3,4}$, Shan $\mathrm{Lu}^{2,3,4}$, Dong Jin ${ }^{2,3,4}$, Ji $\mathrm{Pu}^{2}$, \\ Han Zheng ${ }^{2}$, Junqin $\mathrm{Li}^{1,2}$, Ying Huang ${ }^{2}$, \\ Suping Wang ${ }^{1}$, and Jianguo $\mathrm{Xu}^{1,2,3,4^{\star}}$ \\ ${ }^{1}$ Department of Epidemiology, Shanxi Medical University School of \\ Public Health, Taiyuan, Shanxi 030001, P. R. China \\ ${ }^{2}$ State Key Laboratory of Infectious Disease Prevention and Control, \\ National Institute for Communicable Disease Control and Prevention, \\ Chinese Center for Disease Control and Prevention, Beijing 102206, \\ P. R. China \\ ${ }^{3}$ Shanghai Institute for Emerging and Re-emerging Infectious Diseases, \\ Shanghai Public Health Clinical Center, Shanghai 201508, P. R. China \\ ${ }^{4}$ Research Units of Discovery of Unknown Bacteria and Function, \\ Chinese Academy of Medical Sciences, Beijing 100730, P. R. China \\ (Received Oct 22, 2020 / Revised Jan 18, 2021 / Accepted Feb 9, 2021)
}

Three rod-shaped, Gram-stain-positive, and catalase-positive, phenotypically closely related isolates $\left(\mathrm{HY} 052^{\mathrm{T}}, \mathrm{HY} 050\right.$, and HY045) were obtained from fecal samples collected from bats in Guangxi province and Chongqing city of China. Circular, smooth, light-yellow colonies appeared on brain heart infusion plate after $24-48 \mathrm{~h}$ incubation at $28^{\circ} \mathrm{C}$. The optimal $\mathrm{pH}$ for growth was between 6.0 and 7.5. Based on 16S rRNA, the three isolates were phylogenetically related to Agromyces terreus $\mathrm{DS}-10^{\mathrm{T}}$, Agromyces aureus $\mathrm{AR} 33^{\mathrm{T}}$, Agromyces salentinus 20-5 ${ }^{\mathrm{T}}$, Agromyces allii UMS-62 ${ }^{\mathrm{T}}$, Agromyces lapidis $\mathrm{CD} 55^{\mathrm{T}}$, and Agromyces italicus $\mathrm{CD1}^{\mathrm{T}}$. Moreover, based on 296 core genes, the phylogenomic tree indicated that the three isolates clustered together, closest to Agromyces cerinus VKM Ac$1340^{\mathrm{T}}$ and Agromyces fucosus VKM Ac- $1345^{\mathrm{T}}$ but separated distantly from other Agromyces species. The average nucleotide identity values between strain $\mathrm{HY}^{2} 2^{\mathrm{T}}$ and other $\mathrm{Agro}$ myces species ranged from $79.3 \%$ to $87.9 \%$, lower than the 95-96\% threshold. Furthermore, the genome of strain $\mathrm{HY}^{2}{ }^{\mathrm{T}}{ }^{\mathrm{T}}$ contains a circular chromosome of 3,437,203 bp with $\mathrm{G}+\mathrm{C}$ content of $69.0 \mathrm{~mol} \%$. Main fatty acids were anteiso- $\mathrm{C}_{15: 0}$ and anteiso- $\mathrm{C}_{1700}$. The polar lipids comprised diphosphatidylglycerol, phosphatidylglycerol, and unidentified glycolipids. Rhamnose, ribose, and glucose were the primary cell wall sugars. The major peptidoglycan amino acids included alanine, glutamic acid, glycine, and 2,4-diaminobutyric acid. An additional remarkable difference from other Agromyces species is that MK-12 was the sole menaquinone in strain $\mathrm{HY}^{2} \mathrm{S2}^{\mathrm{T}}$. Based on results from the polyphasic characterizations performed in this study, our isolates are proposed to be members of a novel species in genus Agromyces, named Agromyces

\footnotetext{
*For correspondence. E-mail: xujianguo@icdc.cn

${ }^{5}$ Supplemental material for this article may be found at http://www.springerlink.com/content/120956.

Copyright (C) 2021, The Microbiological Society of Korea
}

\author{
laixinhei. The type strain is $\mathrm{HY}^{052}{ }^{\mathrm{T}}\left(=\mathrm{CGMCC} 1.17175^{\mathrm{T}}=\right.$ \\ JCM $33695^{\mathrm{T}}$ ).
}

Keywords: Agromyces laixinhei sp. nov, bat feces, taxonomy

\section{Introduction}

The COVID-19 pandemic has put the possibility and danger of disease transmission from wildlife to humans in the spotlight again. Our laboratory has investigated the microbiome diversity of wild animals since 2014 to identify potentially pathogenic microbial species and dissect the process of disease transmission. So far, we have analyzed samples from Tibetan antelopes (Wang et al., 2018), plateau pikas (Li et al., 2020), snow finches (Ge et al., 2020), and Tibetan wild asses (Huang et al., 2019), and uncovered novel bacterial species facilitated by whole genome sequencing. Bats, the only flying mammal, are natural reservoirs of Ebola virus and SARS-like coronaviruses (Ge et al., 2012, 2013). However, little is known about the bacterial species associated with bats (Pierlé et al., 2015; Huang et al., 2020), which prompted us to study the composition of their intestinal microbiota. To this end, three novel strains (HY052 $2^{\mathrm{T}}$, HY050, and HY045) were isolated from two bat faecal samples and their taxonomic characterization were described.

The genus Agromyces was first proposed in 1969 (Gledhill and Casida, 1969), and amended later in 1992 and 2004, respectively (Zgurskaya et al., 1992; Ortiz-Martinez et al., 2004). Members of the genus Agromyces are aerobic, non-motile and Gram-stain-positive, with MK-11 and MK-12 as the predominant menaquinones, and anteiso- $\mathrm{C}_{15: 0}$, anteiso- $\mathrm{C}_{17: 0}$, and iso- $\mathrm{C}_{16: 0}$ as the primary fatty acids (Chen et al., 2016; Corretto et al., 2016; Huang et al., 2016). As of the end of 2020 , the genus is comprised of 36 species and two subspecies (http://www.bacterio.net/agromyces.html) with valid published names (Parte, 2018), mostly isolated from various environmental sources such as soil (Chen et al., 2016; Huang et al., 2016), the rhizosphere (Corretto et al., 2016), caves and rocks, plant tissues, sea sediments, and catacombs. Studies directly addressing the importance of Agromyces in its associated ecosystems and its physiology are rare, however, Agromyces likely influences its environment in many ways, e.g., by interacting with other microbes (Casida, 1983). So far, most members of the genus are soil-associated, and some may be opportunistic pathogen (Sridhar et al., 2015), only a few were isolated from other habitats, e.g., fermented seafood (Park et al., 2010), gut of insect larvae and plateau pika (Heo et al., 2020; Li et al., 2020). However, there are a lot of unknowns about this genus that remain to be investigated. Interestingly, some of the products or metabolic capability of the genus Agromyces have huge industrial and ecological 
potential, either by producing enzymes of higher quantity/ quality (Yasuhira et al., 2007; Mitsukawa et al., 2018) or by providing the bioremediation of contaminated soil (Corretto et al., 2016; Zhao et al., 2016).

In this study, we report the phylogenetic position of our three novel strains (HY052 ${ }^{\mathrm{T}}$, HY050, and HY045) and propose that they represent a new species of the genus Agromyces with a polyphasic taxonomic approach.

\section{Materials and Methods}

\section{Isolation of bacterial strains and culture conditions}

A novel bacterial species, Apibacter raozihei (Huang et al., 2020), was recently isolated from Hipposideros and Taphozous spp. bat feces freshly collected between July and September in 2011 by Prof. Zhengli Shi's team (Wuhan Institute of Virology, Chinese Academy of Sciences). In this study, we described the isolation and characterization of another three strains (HY052 ${ }^{\mathrm{T}}$, HY050, and HY045) recovered from the same batch of bat fecal samples. Each fecal sample (1.0 g) was suspended and diluted with $1,000 \mu \mathrm{l}$ of sterile water, and then $150 \mu \mathrm{l}$ of the diluents was spread onto brain heart infusion (BHI) agar medium and incubated at $10-30^{\circ} \mathrm{C}$ for 24-72 h. Different colonies that emerged on the plates were selected, purified, and stored. Bacterial strains were subjected to $16 \mathrm{~S}$ rRNA gene sequence analysis, and three of them (HY052 ${ }^{\mathrm{T}}, \mathrm{HY} 050$, and HY045) were selected for polyphasic characterization. Strain $\mathrm{HY} 052^{\mathrm{T}}$ (deposited in the China General Microbiological Culture Collection Center [CGMCC 1.17175] and Japan Collection of Microorganisms [JCM 33695]) was recovered from a Taphozous spp. fecal sample collected in Chongzuo City $\left(22^{\circ} 20^{\prime} 54^{\prime \prime} \mathrm{N}, 106^{\circ} 49^{\prime} 20^{\prime \prime} \mathrm{E}\right)$ of Guangxi province while strains HY050 and HY045 were isolated from Hipposideros spp. feces in the Changshou District $\left(30^{\circ} 02^{\prime} 15^{\prime \prime} \mathrm{N}, 107^{\circ} 07^{\prime} 4^{\prime \prime} \mathrm{E}\right)$ of Chongqing City, two locations a thousand miles apart.

\section{Phenotypic and biochemical analysis}

Phenotypic characteristics were assessed using a variety of tests on the three isolates, which were aerobically cultured in $\mathrm{BHI}$ medium at $28^{\circ} \mathrm{C}$ for $24-48 \mathrm{~h}$. Gram-stain were performed with a kit according to the manufacturer's instructions. Morphological features of Gram-stained cells were observed using light and electron microscopy. Bacterial growth was monitored every $8 \mathrm{~h}$ for $144 \mathrm{~h}$ at different temperatures $\left(4,15,25,28,30,35\right.$, or $\left.45^{\circ} \mathrm{C}\right)$, with a $\mathrm{pH}$ ranging from 3.0-12.0 (at increments of $1 \mathrm{pH}$ unit adjusted with $1 \mathrm{M} \mathrm{HCL}$ or $\mathrm{NaOH})$ and various concentrations of $\mathrm{NaCl}(0.5,1.0$, $2.0,3.0,4.0,5.0,6.0,7.0,8.0,9.0,10.0$, or $11.0 \%[\mathrm{w} / \mathrm{v}])$. The catalase reaction was determined by an ID Color Catalase kit and oxidase activity was tested with the oxidase reagent. BHI agar best supported growth, compared to plates of Reasoner's 2A Agar, Nutrient Agar, and Mueller-Hinton Broth medium. API 50CH, API 20E strips, and the API ZYM system (bioMérieux) were used following the manufacturer's instructions to test the carbon utilization, acid production and enzyme activity of substrates by strains that were grown on $\mathrm{BHI}$ for 2 days at $28^{\circ} \mathrm{C}$; for carbohydrate fermentation tests, bacteria were suspended in API $50 \mathrm{CHB} / \mathrm{E}$ medium.

\section{Phylogenetic analysis and whole-genome sequencing}

To genetically identify the isolates, $16 \mathrm{~S}$ rRNA genes of strains HY052 $2^{\mathrm{T}}$, HY050, and HY045 were separately amplified by PCR using the universal primers 27F and 1429R (Delgado et al., 2006; Jin et al., 2013). The sequences of the amplified products were determined and compared with their corresponding sequences in the EzBioCloud database (Yoon et al., 2017a) (http://www.ezbio-cloud.net) and GenBank (http:// www.ncbi.nlm.nih.gov/blast) to locate its taxonomic position. After aligning the $16 \mathrm{~S}$ rRNA gene sequences of the type strains in the genus Agromyces using the CLUSTAL_W program (Chen et al., 2007), phylogenetic trees were constructed with three algorithms, Neighbor-Joining (NJ), Maximum-Likelihood (ML), and Maximum-Parsimony (MP), using MEGA $\mathrm{X}$ software (www.megasoftware.net) (Kumar et al., 2016) with a bootstrap analysis of 1,000 replications (Kimura, 1980). Furthermore, the genomic DNA of the isolates (HY052 ${ }^{\mathrm{T}}$, HY050, and HY045) and their closest relatives were extracted with the Wizard Genomic DNA Purification kit (Promega) according to the manufacturer's instructions.

The complete genome of strain $\mathrm{HY}_{052}{ }^{\mathrm{T}}$ was sequenced with the PacBio single Molecule Real-Time technology (Berlin et al., 2015), assembled de novo and analyzed using the HGAP v4 application (Pacific Biosciences, SMRT Link 6.0). Meanwhile, the rest of the strains (HY050, HY045, and all closely related strains) were sequenced on an Illumina sequencing platform. Genome sequence data were used for the following analyses. To verify their phylogenetic position within the genus Agromyces, a phylogenomic tree (Wee et al., 2017) was constructed upon concatenation and alignment of the core genes in MAFFT, using the approximate ML algorithm in FastTree (Price et al., 2009), then processed and edited it in Dendroscope 3 (Huson and Scornavacca, 2012). The 296 core genes were determined based on clustering 25 genomes (those of the three isolates, and 21 of the genus Agromyces plus Arthrobacter globiformis NBRC12137 as the outgroup) using CD-HIT with a 0.4 protein sequence identity threshold.

With the OrthoANIu algorithm (Yoon et al., 2017b) and GGDC 2.1 (Meier-Kolthoff et al., 2013), the ANI and dDDH values of these three isolates were calculated between them and the other related species in the genus Agromyces. After an alignment of the protein sequences by DIAMOND (Buchfink et al., 2015), the phylogenetic classification of protein sequences was analyzed against the cluster of orthologous groups of proteins (COG) database (Galperin et al., 2015). The threshold of protein identity was set at 0.4 . Carbohydrate-active enzymes were predicted using the Carbohydrate-Active enZYmes database (CAZy) (Cantarel et al., 2009). KEGG (Kyoto Encyclopedia of Genes and Genomes) pathway annotation was performed to analyze the function of target genes (Kanehisa et al., 2016). After clustering by USEARCH 11 (Edgar, 2010), the Bacterial Pan Genome Analysis pipeline (BPGA) was used to analyze the pan-genome orthologous groups (POGs) of 24 available Agromyces genomes (those of the three isolates, and 21 of the genus Agromyces) with a 0.4 identity threshold for amino acid sequences. The Circos (http://circos.ca/) (Wyatt et al., 2013) was used to build a circular genome map. 


\section{Chemotaxonomic analyses}

Cellular fatty acids were extracted from saponified and me- thylated material with the Sherlock automatic bacterial identification system and analyzed with gas chromatography. Respiratory quinones were tested using reversed phase high

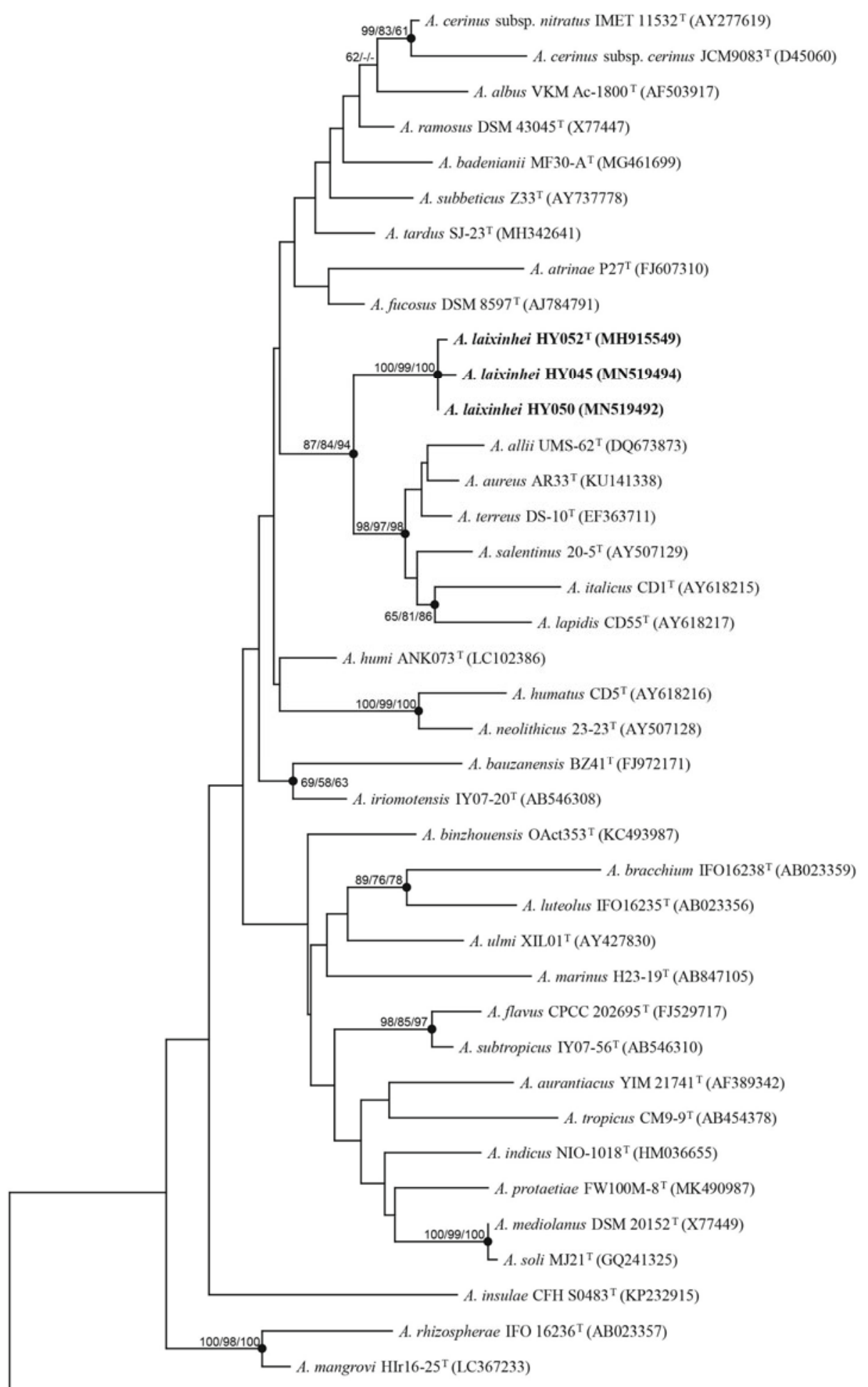

Fig. 1. Neighbor-joining tree based on the 16S rRNA gene sequences from Agromyces species. The tree shows the taxonomic position of strains HY052 ${ }^{\mathrm{T}}$, HY050, and HY045 in the Agromyces genus. Filled circles mean that corresponding nodes are also recovered in trees generated using ML and MP methods. The numerals (values $>50 \%$ are noted) indicate percentage of bootstrap samplings as derived from 1,000 replications. Bar, 0.010 substitutions per nucleotide position. The sequence of Arthrobacter globiformis NBRC $12137^{\mathrm{T}}$ serves as an outgroup. 


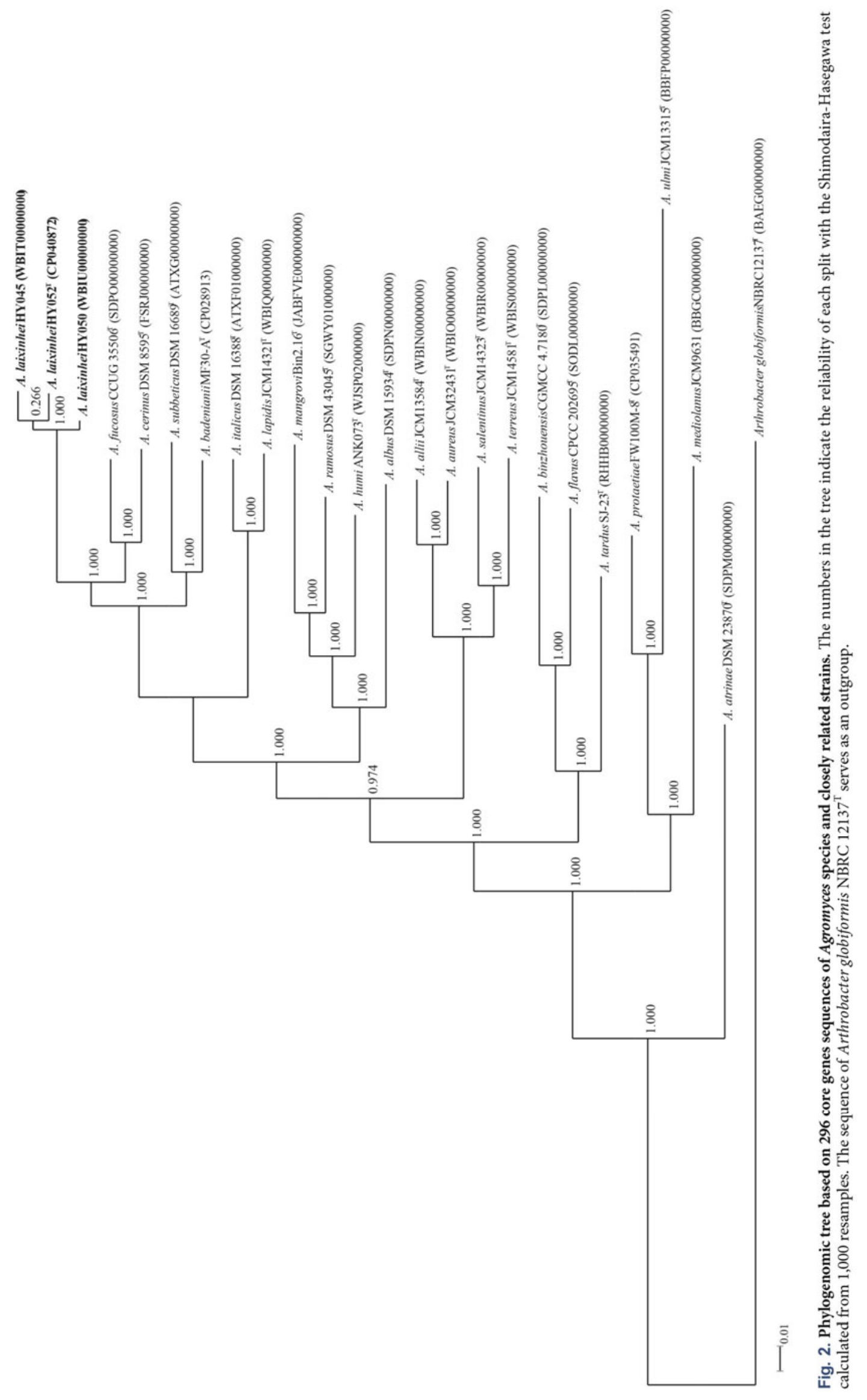


performance liquid chromatography (HPLC). Polar lipids were analyzed with two-dimensional thin-layer chromatography (TLC). Peptidoglycan amino acids were measured with a Hitachi-8900 high speed amino acid analyzer. Cell wall sugars were examined with an established method (Hasegawa et al., 1983).

\section{Nucleotide sequence accession numbers}

The GenBank accession numbers of strains HY052 ${ }^{\mathrm{T}}$, HY050, and HY045 are MH915549, MN519492, and MN519494 (for the 16S rRNA gene) as well as CP040872, WBIU00000000, and WBIT00000000 (for the genome), respectively. Six Supplementary data Figures and four Supplementary data Tables are available with the online Supplementary Materials.

\section{Results and Discussion}

\section{Phylogenetic analysis}

BLAST analysis of the near full-length 16S rRNA gene sequences $(1,491 \mathrm{bp}$ ) on the EzBioCloud database showed that the strain HY052 ${ }^{\mathrm{T}}$ were closely related to A. terreus DS- $10^{\mathrm{T}}$ (98.5\%, similarity), A. aureus AR33 ${ }^{\mathrm{T}}$ (98.3\%), A. salentinus $20-5^{\mathrm{T}}(98.0 \%)$, and $A$. allii UMS-62 ${ }^{\mathrm{T}}(98.0 \%)$. By contrast, our isolates shared high similarity with each other $\left(\mathrm{HY} 052^{\mathrm{T}} v \boldsymbol{s}\right.$. HY050, 99.9\%; HY052 $2^{\mathrm{T}}$ vs. HY045, 99.8\%; HY050 vs. HY045, $100 \%)$. The topologies of the three trees generated using NJ, ML, and MP methods were similar (Fig. 1, Supplementary data Figs. S1 and 2), with the three unknown isolates clustering together to form a distinct branch affiliated with members of the genus Agromyces. The closest cluster near that novel branch included six species of the genus Agromyces (A. terreus DS- $10^{\mathrm{T}}$, A. aureus $\mathrm{AR} 33^{\mathrm{T}}$, A. salentinus $20-5^{\mathrm{T}}, A$. allii $\mathrm{UMS}-62^{\mathrm{T}}$, A. lapidis $\mathrm{CD} 55^{\mathrm{T}}$, and $A$. italicus $\mathrm{CD} 1^{\mathrm{T}}$ ), are similar to the 16S rRNA gene BLAST results. The phylogenomic tree based on 296 core genes (Supplementary data
Table S1) illustrated that our three isolates cluster together, closest to A. cerinus VKM Ac- $1340^{\mathrm{T}}$ and A. fucosus VKM Ac$1345^{\mathrm{T}}$ but separated distantly from other Agromyces species. These results further support a novel species status for our isolates (Fig. 2). Thus, according to the above results, A. allii UMS-62 ${ }^{\mathrm{T}}\left(=\mathrm{JCM} 13584^{\mathrm{T}}\right)$, A. aureus $\mathrm{AR} 33^{\mathrm{T}}\left(=\mathrm{JCM} 32431^{\mathrm{T}}\right)$, A. cerinus VKM Ac- $1340^{\mathrm{T}}\left(=\mathrm{JCM} 9083^{\mathrm{T}}\right)$, A. fucosus VKM Ac- $1345^{\mathrm{T}}\left(=\right.$ CCUG $\left.35506^{\mathrm{T}}\right)$, A. italicus $\mathrm{CD}^{\mathrm{T}}\left(=\mathrm{JCM} 14320^{\mathrm{T}}\right)$, A. lapidis $\mathrm{CD}^{2} 5^{\mathrm{T}}\left(=\mathrm{JCM} 14321^{\mathrm{T}}\right)$, A. salentinus $20-5^{\mathrm{T}}(=\mathrm{JCM}$ $\left.14323^{\mathrm{T}}\right)$, and $A$. terreus DS- $10^{\mathrm{T}}\left(=\mathrm{JCM} 14581^{\mathrm{T}}\right)$ were selected for further comparative tests and purchased from collection centers (Japan Collection of Microorganisms, Ibaraki, Japan, JCM; Culture Collection of University of Göteborg, Sweden, CCUG). ANI and dDDH values between strain $\mathrm{HY} 052^{\mathrm{T}}$ and the other two isolates were $99.1-99.2 \%$ and $92.3-93.4 \%$, respectively, indicating that they belong to the same species. Moreover, the ANI and dDDH values between strains HY050 and HY045 were $98.9 \%$ and $90.8 \%$, suggesting that the two isolates were clonally different. By contrast, the ANI values between strain $\mathrm{HY} 052^{\mathrm{T}}$ and other Agromyces species ranged from 79.3 to $87.9 \%$ (Table 1), lower than the $95-96 \%$ threshold for delineating species (Richter and Rossello-Mora, 2009; Chun et al., 2018). Similarly, the dDDH values between strain $\mathrm{HY}_{052^{\mathrm{T}}}$ and other Agromyces species ranged from 22.5 to $31.0 \%$ (Table 1), also much lower than the threshold of $70 \%$ (Wayne, 1988). Both ANI and dDDH results (Table 1) demonstrated that our isolates represent a novel species in the genus Agromyces.

\section{Whole genome characteristics and functional gene annotation}

SMRT sequencing of strain $\mathrm{HY} 052^{\mathrm{T}}$ yielded a circular chromosome (no plasmid sequence was present) of 3,437,203 bp in size, containing 3,235 genes (including $45 \mathrm{tRNA}$ and six rRNA genes) with a DNA G + C content of $69.0 \mathrm{~mol} \%$, which is similar to the genomic characteristics of strains HY050 and HY045 (Supplementary data Table S2). However, the G +

Table 1. The $16 \mathrm{~S}$ rRNA gene similarity, dDDH, ANI results between $\mathrm{HY} 052^{\mathrm{T}}$ and related strains

\begin{tabular}{|c|c|c|c|c|c|}
\hline Species & 16S rRNA similarity (\%) & Whole genome GenBank accession No. & $\mathrm{G}+\mathrm{C}(\mathrm{mol} \%)$ & dDDH (\%) & ANI (\%) \\
\hline $\mathrm{HY}^{2} 52^{\mathrm{T}}$ & - & СР040872 & 69.0 & - & - \\
\hline HY050 & 99.9 & WBIU00000000 & 69.0 & 92.3 & 99.1 \\
\hline HY045 & 99.8 & WBIT00000000 & 68.9 & 93.4 & 99.2 \\
\hline A. terreus DS- $10^{\mathrm{T}}$ & 98.5 & WBIS00000000 & 71.1 & 23.0 & 80.1 \\
\hline A. aureus $\mathrm{AR} 33^{\mathrm{T}}$ & 98.3 & WBIO00000000 & 70.4 & 23.0 & 85.1 \\
\hline A. salentinus $20-5^{\mathrm{T}}$ & 98.0 & WBIR00000000 & 70.9 & 22.5 & 79.3 \\
\hline A. allii UMS- $62^{\mathrm{T}}$ & 98.0 & WBIN00000000 & 70.8 & 23.1 & 79.7 \\
\hline A. iriomotensis IY07-20 ${ }^{\mathrm{T}}$ & 97.9 & - & - & - & - \\
\hline A. ramosus KCC A- $0108^{\mathrm{T}}$ & 97.9 & SGWY00000000 & 71.3 & 23.6 & 85.1 \\
\hline A. lapidis $\mathrm{CD} 55^{\mathrm{T}}$ & 97.7 & WBIQ00000000 & 70.9 & 23.9 & 81.1 \\
\hline A. marinus $\mathrm{H} 23-8^{\mathrm{T}}$ & 97.7 & - & - & - & - \\
\hline A. neolithicus $23-23^{\mathrm{T}}$ & 97.6 & - & - & - & - \\
\hline A. $\operatorname{tardus~SJ-23^{\mathrm {T}}}$ & 97.6 & RHHB00000000 & 71.8 & 23.4 & 80.1 \\
\hline A. italicus $\mathrm{CD}^{\mathrm{T}}$ & 97.5 & WBIP00000000 & 70.2 & 23.8 & 85.3 \\
\hline A. humatus $\mathrm{CD}^{\mathrm{T}}$ & 97.5 & - & - & - & - \\
\hline A. subbeticus $\mathrm{Z} 33^{\mathrm{T}}$ & 97.2 & ATXG00000000 & 69.1 & 27.0 & 86.3 \\
\hline A. cerinus VKM Ac- $1340^{\mathrm{T}}$ & 97.2 & FSRJ00000000 & 70.0 & 31.0 & 87.9 \\
\hline A. fucosus VKM Ac- $1345^{\mathrm{T}}$ & 97.1 & SDPO00000000 & 70.1 & 30.2 & 87.5 \\
\hline
\end{tabular}

- indicates that a public genome does not exist in GenBank, so there is no $\mathrm{G}+\mathrm{C}$ content, $\mathrm{dDDH}$, and ANI value. 
C content range (68.9-69.0 mol\%) of our three strains was slightly lower than those of other related species (70.0-71.1 mol\%). A pan-genome analysis showed that the strains HY$052^{\mathrm{T}}, \mathrm{HY} 050$, and HY045 have 73,113 , and 104 unique genes as well as 2,654, 2,665, and 2,725 accessory genes, respectively (Supplementary data Table S3). In particular, the 73 unique genes to strain $\mathrm{HY} 052^{\mathrm{T}}$ are notably fewer than those unique to other strains in the genus Agromyces (115-1880 genes). Of these 73 unique genes, 27 are assumed to encode for unique hypothetical proteins, including deadenylate cyclase, polyketide cyclase, bacterial regulatory proteins and others.

The distribution of genes in the KEGG functional categories showed that our strains and those of the eight closely related species possess many similar pathways in carbohydrate metabolism and amino acid metabolism (Supplementary data Table S4). Of note, the strain $\mathrm{HY}_{05} 2^{\mathrm{T}}$ has a complete shikimate pathway, almost the exclusive biochemical way to obtain aromatic compounds. This pathway enables it to utilize phosphoenolpyruvate and erythrose-4P as raw material to produce not only aromatic amino acids but also aromatic precursors for biosynthesis of secondary metabolites (Lai et al., 2017). Thus, researchers are striving to leverage the shikimate pathways of microbial systems for bulk and fine chemical production (Noda and Kondo, 2017; Averesch and Kromer, 2018).

A CAZy analysis of 135 genes in the strain $\mathrm{HY}_{052^{\mathrm{T}}}$ genome that encode carbohydrate active enzymes revealed that 64 $(47.4 \%)$ are predicted to be glycoside hydrolases (GH), 39 (28.9\%) to be glycosyltransferases (GT), and $28(20.7 \%)$ to be carbohydrate-binding modules (CBM), a profile within the range of its closest relatives (43.1-52.6\% for GH, 23.7$33.9 \%$ for GT, and $15.9-20.9 \%$ for CBM). Among all carbohydrate active enzymes, $\mathrm{GH}$ are the most abundant for the purposes of degrading polysaccharides into smaller products (Berlemont and Martiny, 2016). Strain HY052 $2^{\mathrm{T}}$ has genes encoding up to $29 \mathrm{GH}$-like enzyme families, consistent with its biochemical profile (Table 2) of being able to utilize $\beta$ galactosidase (GH1), $\alpha$-glucosidase (GH13), $\beta$-glucosidase (GH3), and $\mathrm{N}$-acetyl- $\beta$-glucosaminidase (GH84).

A total of 2,759 $\left(\mathrm{HY}^{2} 52^{\mathrm{T}}\right), 2,782$ (HY050), and 2,815 (HY$045)$ genes were assigned in the COG database. Among the 23 COG functional categories (Supplementary data Fig. S3) the genomes of strains HY052 ${ }^{\mathrm{T}}$, HY050, and HY045 were comprised of roughly $10 \%$ of genes belonging to the four largest categories (Supplementary data Fig. S4), i.e., amino acid transport and metabolism (10.0/10.4/10.0\%), carbohydrate transport and metabolism (9.1/9.0/9.2\%), transcription (10.1/9.8/9.9\%), and general functions (10.3/10.0/10.3\%). These strains had profiles similar to their closest neighbors (9.9-10.9\%, 9.4-11.2\%, 8.8-10.8\%, and 9.9-11.5\%).

\section{Phenotypic and biochemical characteristics}

The strain HY052 ${ }^{\mathrm{T}}$ cells were aerobic, Gram-stain-positive, oxidase-negative, catalase-positive, non-spore-forming, nonflagellated rods $0.3-0.7 \times 0.3-3.0 \mu \mathrm{m}$ in size (Supplementary data Fig. S5) that formed circular, smooth, and light-yellow colonies. The growth of strains HY052 ${ }^{\mathrm{T}}, \mathrm{HY} 050$, and HY045 occurred at 15 and $35^{\circ} \mathrm{C}\left(28^{\circ} \mathrm{C}\right.$ was optimum $)$ but not at 4 or $45^{\circ} \mathrm{C}$. Growth also occurred at pH 5.0 and 9.5 (6.0-7.5 was optimum) but not at $\mathrm{pH} 4.0$ or 10.0. Finally, growth oc-

Table 2. Phenotypic characteristics that differentiate Agromyces laixinhei sp. nov. from phylogenetically related species

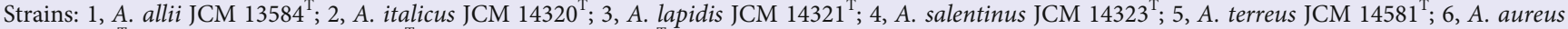
JCM $32431^{\mathrm{T}} ; 7$, A. fucosus CCUG $35506^{\mathrm{T}} ; 8$, A. cerinus JCM $9083^{\mathrm{T}}$. All strains were grown in BHI medium, $28^{\circ} \mathrm{C}$.

+, Positive; -, negative; w, weakly positive; NA, not available.

\begin{tabular}{|c|c|c|c|c|c|c|c|c|c|c|c|}
\hline Characteristic & $\mathrm{HY} 052^{\mathrm{T}}$ & HY050 & HY045 & 1 & 2 & 3 & 4 & 5 & 6 & 7 & 8 \\
\hline Optimal temperature $\left({ }^{\circ} \mathrm{C}\right)$ & 28 & 28 & 28 & $30^{\mathrm{a}}$ & $28^{\mathrm{b}}$ & $28^{\mathrm{b}}$ & $20-28^{c}$ & $26^{\mathrm{d}}$ & $28^{\mathrm{e}}$ & $26-30^{f}$ & $28^{\mathrm{f}}$ \\
\hline Halotolerance $(\mathrm{NaCl} ; \%, \mathrm{w} / \mathrm{v})$ & 4.5 & 4.5 & 4.5 & $3^{\mathrm{a}}$ & $4^{\mathrm{b}}$ & $4^{\mathrm{b}}$ & $4^{\mathrm{c}}$ & $6^{\mathrm{d}}$ & $3^{\mathrm{e}}$ & $4^{\mathrm{f}}$ & $7^{\mathrm{f}}$ \\
\hline Optimal $\mathrm{pH}$ range & $6.0-7.5$ & $6.0-7.5$ & $6.0-7.5$ & $6.5-7.5^{\mathrm{a}}$ & $5-9.5^{\mathrm{b}}$ & $5-9.5^{\mathrm{b}}$ & NA & $4.5-10.5^{\mathrm{d}}$ & $6.5-7.5^{\mathrm{e}}$ & NA & NA \\
\hline Major menaquinone & 12 & 12 & 12 & $11,12^{\mathrm{a}}$ & $12,13^{\mathrm{b}}$ & $12,13^{\mathrm{b}}$ & $12,11^{\mathrm{c}}$ & $10,11,12^{\mathrm{d}}$ & $11,10,12^{\mathrm{e}}$ & $12^{\mathrm{f}}$ & $\mathrm{NA}$ \\
\hline \multicolumn{12}{|l|}{ Enzyme activity: } \\
\hline Esterase (C4) & - & - & - & - & + & + & $\mathrm{w}$ & - & - & - & + \\
\hline Valine arylamidase & - & - & - & - & - & $\mathrm{w}$ & - & - & $\mathrm{w}$ & $\mathrm{w}$ & - \\
\hline Cystine arylamidase & - & - & - & - & - & $\mathrm{w}$ & - & - & $\mathrm{w}$ & $\mathrm{w}$ & - \\
\hline Acid phosphatase & - & - & - & - & - & - & - & - & $\mathrm{w}$ & - & $\mathrm{w}$ \\
\hline$\beta$-Galactosidase & - & - & - & $\mathrm{w}$ & $\mathrm{w}$ & - & + & - & + & $\mathrm{w}$ & + \\
\hline N-Acetyl- $\beta$-glucosaminidase & $\mathrm{w}$ & $\mathrm{w}$ & + & - & - & - & - & - & - & - & - \\
\hline Gelatinase & - & - & - & - & + & - & - & - & - & + & - \\
\hline Citrate utilization & + & $\mathrm{w}$ & $\mathrm{w}$ & - & - & - & - & $\mathrm{w}$ & - & - & - \\
\hline \multicolumn{12}{|l|}{ Acid production from: } \\
\hline D-Galactose & - & - & - & - & $\mathrm{w}$ & + & + & + & + & $\mathrm{w}$ & + \\
\hline D-Glucose & - & - & - & + & + & + & + & + & + & + & + \\
\hline L-Rhamnose & - & - & - & + & - & - & + & + & + & $\mathrm{w}$ & + \\
\hline D-Mannitol & + & + & + & - & - & - & - & - & $\mathrm{w}$ & - & - \\
\hline D-Turanose & - & - & - & - & $\mathrm{w}$ & - & $\mathrm{w}$ & $\mathrm{w}$ & $\mathrm{w}$ & $\mathrm{w}$ & $\mathrm{w}$ \\
\hline Potassium gluconate & + & $\mathrm{w}$ & $\mathrm{w}$ & - & $\mathrm{w}$ & - & - & - & - & - & - \\
\hline Potassium 5-keto-gluconate & + & $\mathrm{w}$ & $\mathrm{w}$ & - & - & - & - & - & - & - & - \\
\hline
\end{tabular}


curred in the presence of 0 to $4.5 \%$ (w/v) $\mathrm{NaCl}$ (Table 2). The differential biochemical characteristics of strain $\mathrm{HY} 052^{\mathrm{T}}$ from closely related species are summarized in Table 2 . In addition, all species (HY052 ${ }^{\mathrm{T}}$, HY050, HY045, and all eight related type strains) produced acid from polychrome esculine citrate, maltose, starch, and glycogen but not from amygdalin, arabinose, D-adonitol, D-arabitol, D-fucose, D-sorbitol, D-tagatose, dulcitol, D-xylose, erythritol, glucose, inositol, inositol, L-arabitol, L-sorbose, L-xylose, melezitose, melibiose, methyl $\alpha$-D-glucopyranoside, methyl $\beta$-D-xylopyranoside, potassium 2-keto-gluconate, sorbitol rhamnose, sucrose, or xylitol. Moreover, all tested species were positive for naphthol-AS-BI-phosphohydrolase, $\beta$-galactosidase, and acetoin production but negative for alkaline phosphatase, lipase (C14), trypsin, $\alpha$-chymotrypsin, $\beta$-glucuronidase, $\alpha$ mannosidase, $\alpha$-fucosidase, arginine dihydrolase, lysine decarboxylase, ornithine decarboxylase, $\mathrm{H}_{2} \mathrm{~S}$ production, urea hydrolysis, deaminase, or indole production.

\section{Chemotaxonomic characteristics}

As detailed in Table 3, the major cellular fatty acids of strains $\mathrm{HY}_{052}{ }^{\mathrm{T}}$, HY050, and HY045 were anteiso- $\mathrm{C}_{15: 0}(36.9 \%$, $37.2 \%, 38.0 \%)$ and anteiso- $\mathrm{C}_{17: 0}(31.8 \%, 35.4 \%, 35.7 \%)$, in contrast to the lower average proportion of anteiso- $\mathrm{C}_{17: 0}$ in the related type strains $(25.9 \%)$. MK-12 is the sole menaquinone in strain $\mathrm{HY} 052^{\mathrm{T}}$, distinctively different from most Agromyces species with more than one menaquinone, either predominant or minor (Table 2). The major polar lipids (Supplementary data Fig. S6) were diphosphatidylglycerol (DPG), phosphatidylglycerol (PG), and unidentified glycolipids (GL1-2). Rhamnose, ribose, and glucose were the primary cell wall sugars for strain HY052 $2^{\mathrm{T}}$. The peptidoglycan amino acids in $\mathrm{HY} 052^{\mathrm{T}}$ included alanine, glutamic, glycine, and 2,4-diaminobutyric acid.

\section{Taxonomic conclusion}

The topologies based on core genes and 16S rRNA gene sequences of strains HY052 ${ }^{\mathrm{T}}$, HY050, and HY045 using NJ, ML, and MP methods (Fig. 1, Supplementary data Figs. S1 and 2) indicated that they are members of the genus Agromyces, while these three unknown strains clustered together and were distinguishable from its closest phylogenetic neighbors $\left(A\right.$. terreus DS- $10^{\mathrm{T}}, A$. aureus $\mathrm{AR} 33^{\mathrm{T}}$, A. salentinus $20-5^{\mathrm{T}}$, A. allii UMS-62 $2^{\mathrm{T}}$, A. lapidis $\mathrm{CD}^{2} 5^{\mathrm{T}}$, A. italicus $\mathrm{CD} 1^{\mathrm{T}}$, A. cerinus VKM Ac- $1340^{\mathrm{T}}$, and A. fucosus VKM Ac- $1345^{\mathrm{T}}$ ). Moreover, strains HY052 ${ }^{\mathrm{T}}$, HY050, and HY045 can were distinguished from the related type strains and each other by ANI and $\mathrm{dDDH}$ (Table 1), along with other differences among gene similarity, and the genome sequence characteristics of strain $\mathrm{HY}_{052}{ }^{\mathrm{T}}$ as well as the related type species (Table 1 and Supplementary data Table S2). The growth temperature, $\mathrm{pH}$, and $\mathrm{NaCl}$ range of strains $\mathrm{HY} 052^{\mathrm{T}}, \mathrm{HY} 050$, and $\mathrm{HY} 045$ were like other related strains in the genus Agromyces. However, in sharp contrast to the results from their closest relatives, only these three strains were negative for $\beta$-galactosidase activity and acid production from $\mathrm{D}$-glucose, in addition to being positive for $\mathrm{N}$-acetyl- $\beta$-glucosaminidase activity and acid production from potassium 5-keto-gluconate (Table 2). Despite the homogeneous biochemical profile of our three novel isolates (Table 2), there are some small variations: strain $\mathrm{HY} 052^{\mathrm{T}}$ was positive for citrate utilization as well as acid production from both potassium gluconate and potassium 5-keto-gluconate whereas the other two strains were only weak positives for all these three test. Conversely, strain HY045 was positive for $\mathrm{N}$-acetyl- $\beta$-glucosaminidase while the other two were weak positive.

Based on the phylogenetic, physiological, and chemotaxonomic characterizations, we suggest that strains $\mathrm{HY}_{05} 2^{\mathrm{T}}$, HY050, and HY045 represent a novel species of the genus Agromyces, for which the name Agromyces laixinhei sp. nov. is proposed.

\section{Description of Agromyces laixinhei sp. nov.}

Agromyces laixinhei (lai.xin.he'i. N.L. gen. n. laixinhei of Dr. Xin-He Lai, for his persistent enthusiasm in microbiology, significant contribution to Francisella pathogenesis research and unwavering commitment to bacterial taxonomy).

Cells are aerobic, Gram-stain-positive, catalase-positive, nonmotile, rod-shaped, $0.3-0.7 \times 0.3-3.0 \mu \mathrm{m}$ in size, forming circular, smooth and light-yellow colonies. Growth occurs after $24-48 \mathrm{~h}$ at temperatures between 15 and $35^{\circ} \mathrm{C}$ (optimum, $28^{\circ} \mathrm{C}$ ) on $\mathrm{BHI}$ plates with an optimal $\mathrm{pH}$ between 6.0 and 7.5. Growth is modest in the presence of $4.5 \%(\mathrm{w} / \mathrm{v})$ $\mathrm{NaCl}$ (optimum, 0.5-1.0\%). Oxidase negative. Main fatty acids are anteiso- $\mathrm{C}_{15: 0}$ and anteiso- $\mathrm{C}_{17: 0}$. MK-12 is the sole menaquinone. Polar lipids comprise DPG, PG, and GL1-2. Rhamnose, ribose and glucose are the primary cell wall sugars. The major peptidoglycan amino acids are alanine, glutamic acid, glycine, and 2,4-diaminobutyric acid. Acid is produced from D-mannitol, D-xylose, glycerol, glycogen, Larabinose, maltose, polychrome esculine citrate, potassium 5-keto-gluconate (weakly by strains HY050 and HY045), potassium gluconate (weakly by strains HY050 and HY045), salicin, and starch. Weak acid production from arbutin, D-

Table 3. Fatty acid compositions of Agromyces laixinhei sp. nov. and closely related strains

Strains: 1, A. allii JCM13584 ${ }^{\mathrm{T}}$; 2, A. italicus JCM $14320^{\mathrm{T}} ; 3$, A. lapidis JCM $14321^{\mathrm{T}}$; 4, A. salentinus $\mathrm{JCM}_{14323^{\mathrm{T}}}$; 5, A. terreus JCM14581 ${ }^{\mathrm{T}}$; 6 , A. aureus $\mathrm{JCM}^{\mathrm{T}}$ $32431^{\mathrm{T}} ; 7$, A. fucosus CCUG $35506^{\mathrm{T}} ; 8$, A. cerinus JCM $9083^{\mathrm{T}}$; ND, not detected.

\begin{tabular}{|c|c|c|c|c|c|c|c|c|c|c|c|}
\hline Fatty acid & $\mathrm{HY}_{052^{\mathrm{T}}}$ & HY050 & HY045 & 1 & 2 & 3 & 4 & 5 & 6 & 7 & 8 \\
\hline iso- $\mathrm{C}_{15: 0}$ & 11.0 & 10.9 & 9.3 & 6.2 & 5.7 & 6.9 & 11.1 & 16.4 & 6.6 & 11.7 & 8.7 \\
\hline anteiso- $\mathrm{C}_{15: 0}$ & 36.9 & 37.2 & 38.0 & 33.9 & 39.5 & 35.0 & 31.7 & 28.7 & 42.3 & 42.6 & 42.9 \\
\hline anteiso- $\mathrm{C}_{15: 1} \mathrm{~A}$ & 3.4 & ND & 1.2 & 6.3 & 6.3 & 6.7 & 6.1 & 3.6 & 3.7 & 0.4 & 5.5 \\
\hline iso- $\mathrm{C}_{16: 0}$ & 9.8 & 9.9 & 9.2 & 20.1 & 20.4 & 22.4 & 13.9 & 16.0 & 19.9 & 11.5 & 9.8 \\
\hline iso- $\mathrm{C}_{17: 0}$ & 5.1 & 5.5 & 4.3 & 2.9 & 1.2 & 1.9 & 4.9 & 8.1 & 2.2 & 3.7 & 3.1 \\
\hline anteiso- $\mathrm{C}_{17: 0}$ & 31.8 & 35.4 & 35.7 & 27.1 & 24.3 & 24.5 & 28.4 & 23.2 & 22.7 & 27.6 & 27.6 \\
\hline
\end{tabular}


arabinose, D-fructose, D-mannose, and trehalose. However, acid is not produced from amygdalin, cellobiose, D-adonitol, $\mathrm{D}$-arabitol, D-fucose, D-galactose, D-glucose, D-ribose, Dsorbitol, D-tagatose, D-turanose, dulcitol, D-xylose, erythritol, gentiobiose, inositol, inulin, lactose, L-arabitol, L-fucose, L-rhamnose, L-sorbose, L-xylose, melezitose, melibiose, methyl $\beta$-D-xylopyranoside, methyl $\alpha$-D-glucopyranoside, methyl $\alpha$-D-mannopyranoside, $\mathrm{N}$-acetylglucosamine, potassium 2-keto-gluconate, raffinose, sucrose, or xylitol. Positive for leucine arylamidase, naphthol-AS-BI-phosphohydrolase, $\alpha$-glucosidase, and $\mathrm{N}$-acetyl- $\beta$-glucosaminidase (weakly in strains HY052 $2^{\mathrm{T}}$ and HY050). Weakly positive for $\beta$-glucosidase. Negative for acid phosphatase, alkaline phosphatase, cystine arylamidase, esterase (C4), esterase lipase (C8), lipase (C14), trypsin, valine arylamidase, $\alpha$-chymotrypsin, $\alpha$-fucosidase, $\alpha$-galactosidase, $\alpha$-mannosidase, $\beta$-galactosidase, or $\beta$-glucuronidase. Positive for citrate utilization (weakly by strains HY050 and HY045) and acetoin production but negative for tryptophan deaminase, arginine dihydrolase, lysine decarboxylase, ornithine decarboxylase, $\mathrm{H}_{2} \mathrm{~S}$ production, urea hydrolysis, deaminase, indole production or gelatinase. Also negative for utilization of glucose, mannitol, inositol, sorbitol, rhamnose, sucrose, melibiose, amygdalin, or arabinose.

The type strain HY052 ${ }^{\mathrm{T}}\left(=\mathrm{CGMCC} 1.17175^{\mathrm{T}}=\mathrm{JCM} 33695^{\mathrm{T}}\right)$, isolated from bat fecal sample of the Taphozous spp. in the Guangxi province of China, has a DNA G + C content of $69.0 \mathrm{~mol} \%$. The GenBank accession numbers of strains HY$052^{\mathrm{T}}$, HY050, and HY045 are MH915549, MN519492, and MN519494 (for the 16S rRNA gene sequence), as well as CP040872, WBIU00000000, and WBIT00000000 (for thewhole genome), respectively.

\section{Acknowledgments}

The authors thank professors Zhengli Shi and Peng Zhou (Wuhan Institute of Virology, Chinese Academy of Sciences) for sharing the bat fecal samples.

This work was supported by grants from National Science and Technology Major Project of China (2018ZX10712001018, 2017ZX10303405-002, 2017ZX10303405-005-002), National Science and Technology of China (2017FY101202), National Key R\&D Program of China (2019YFC1200500 and 2019YFC1200505), Sanming Project of Medicine in Shenzhen (SZSM201811071), and Research Units of Discovery of Unknown Bacteria and Function (2018RU010).

\section{Conflict of Interest}

The authors declare that there are no conflicts of interest.

\section{Ethical Statement}

The ethical practice was approved by Ethical Committee of the National Institute fo Communicable Disease Control and Prevention, Chinese Center for Disease Control and Prevention (\# ICDC-2016004).

\section{References}

Averesch, N.J.H. and Krömer, J.O. 2018. Metabolic engineering of the shikimate pathway for production of aromatics and derived compounds-present and future strain construction strategies. Front. Bioeng. Biotechnol. 6, 32.

Berlemont, R. and Martiny, A.C. 2016. Glycoside hydrolases across environmental microbial communities. PLoS Comput. Biol. 12, e1005300.

Berlin, K., Koren, S., Chin, C.S., Drake, J.P., Landolin, J.M., and Phillippy, A.M. 2015. Assembling large genomes with singlemolecule sequencing and locality-sensitive hashing. Nat. Biotechnol. 33, 623-630.

Buchfink, B., Xie, C., and Huson, D.H. 2015. Fast and sensitive protein alignment using DIAMOND. Nat. Methods 12,59-60.

Cantarel, B.L., Coutinho, P.M., Rancurel, C., Bernard, T., Lombard, V., and Henrissat, B. 2009. The Carbohydrate-Active EnZymes database (CAZy): an expert resource for glycogenomics. Nucleic Acids Res. 37, D233-D238.

Casida, L.E.Jr. 1983. Interaction of Agromyces ramosus with other bacteria in soil. Appl. Environ. Microbiol. 46, 881-888.

Chen, Z., Guan, Y., Wang, J., and Li, J. 2016. Agromyces binzhouensis sp. nov., an actinobacterium isolated from a coastal wetland of the Yellow River Delta. Int. J. Syst. Evol. Microbiol. 66, 2278-2283.

Chen, Y.G., Li, H.M., Li, Q.Y., Chen, W., and Cui, X.L. 2007. Phylogenetic diversity of culturable bacteria in the ancient salt deposits of the Yipinglang Salt Mine, P. R. China. Acta Microbiol. Sin. 47, 571-577.

Chun, J., Oren, A., Ventosa, A., Christensen, H., Arahal, D.R., da Costa, M.S., Rooney, A.P., Yi, H., Xu, X.W., and De Meyer, S. 2018. Proposed minimal standards for the use of genome data for the taxonomy of prokaryotes. Int. J. Syst. Evol. Microbiol. 68, 461-466.

Corretto, E., Antonielli, L., Sessitsch, A., Compant, S., Gorfer, M., Kuffner, M., and Brader, G. 2016. Agromyces aureus sp. nov., isolated from the rhizosphere of Salix caprea L. grown in a heavymetal-contaminated soil. Int. J. Syst. Evol. Microbiol. 66, 37493754.

Delgado, S., Suárez, A., and Mayo, B. 2006. Identification of dominant bacteria in feces and colonic mucosa from healthy Spanish adults by culturing and by $16 \mathrm{~S}$ rDNA sequence analysis. Dig. Dis. Sci. 51, 744-751.

Edgar, R.C. 2010. Search and clustering orders of magnitude faster than BLAST. Bioinformatics 26, 2460-2461.

Galperin, M.Y., Makarova, K.S., Wolf, Y.I., and Koonin, E.V. 2015. Expanded microbial genome coverage and improved protein family annotation in the COG database. Nucleic Acids Res. 43, D261-D269.

Ge, X.Y., Li, J.L., Yang, X.L., Chmura, A.A., Zhu, G., Epstein, J.H., Mazet, J.K., Hu, B., Zhang, W., Peng, C., et al. 2013. Isolation and characterization of a bat SARS-like coronavirus that uses the ACE2 receptor. Nature 503, 535-538.

Ge, X., Li, Y., Yang, X., Zhang, H., Zhou, P., Zhang, Y., and Shi, Z. 2012. Metagenomic analysis of viruses from bat fecal samples reveals many novel viruses in insectivorous bats in China. J. Virol. 86, 4620-4630.

Ge, Y., Yang, J., Lai, X.H., Zhang, G., Jin, D., Lu, S., Wang, B., Huang, Y., Huang, Y., Ren, Z., et al. 2020. Vagococcus xieshaowenii sp. nov., isolated from snow finch (Montifringilla taczanowskii) cloacal content. Int. J. Syst. Evol. Microbiol. 70, 2493-2498.

Gledhill, W.E. and Casida, L.E. 1969. Predominant catalase-negative soil bacteria. III. Agromyces, gen. n., microorganisms intermediary to Actinomyces and Nocardia. Appl. Microbiol. 18, 340-349.

Hasegawa, T., Takizawa, M., and Tanida, S. 1983. A rapid analysis for chemical grouping of aerobic actinomycetes. J. Gen. Appl. 
Microbiol. 29, 319-322.

Heo, J., Hamada, M., Tamura, T., Saito, S., Lee, S.D., Kim, J.S., Hong, S.B., Kwon, S.W., and Kim, S.J. 2020. Agromyces protaetiae sp. nov., isolated from gut of larva of Protaetia brevitarsis seulensis. Int. J. Syst. Evol. Microbiol. 70, 1259-1265.

Huang, J.R., Ming, H., Li, S., Meng, X.L., Zhang, J.X., Khieu, T.N., Tang, Z., Li, W.J., and Nie, G.X. 2016. Agromyces insulae sp. nov., an actinobacterium isolated from a soil sample. Int. J. Syst. Evol. Microbiol. 66, 2002-2007.

Huang, Y., Wang, X., Yang, J., Lu, S., Lai, X.H., Jin, D., Pu, J., Huang, Y., Ren, Z., Zhu, W., et al. 2019. Nocardioides yefusunii sp. nov., isolated from Equus kiang (Tibetan wild ass) faeces. Int. J. Syst. Evol. Microbiol. 69, 3629-3635.

Huang, Y., Wang, X., Yang, J., Lu, S., Lai, X.H., Jin, D., Pu, J., Huang, Y., Ren, Z., Zhu, W., et al. 2020. Apibacter raozihei sp. nov. isolated from bat feces of Hipposideros and Taphozous spp. Int. J. Syst. Evol. Microbiol. 70, 611-617.

Huson, D.H. and Scornavacca, C. 2012. Dendroscope 3: an interactive tool for rooted phylogenetic trees and networks. Syst. Biol. 61, 1061-1067.

Jin, D., Chen, C., Li, L., Lu, S., Li, Z., Zhou, Z., Jing, H., Xu, Y., Du, P., Wang, H., et al. 2013. Dynamics of fecal microbial communities in children with diarrhea of unknown etiology and genomic analysis of associated Streptococcus lutetiensis. BMC Microbiol. 13, 141.

Jung, S.Y., Lee, S.Y., Oh, T.K., and Yoon, J.H. 2007. Agromyces allii sp. nov., isolated from the rhizosphere of Allium victorialis var. platyphyllum. Int. J. Syst. Evol. Microbiol. 57, 588-593.

Jurado, V., Groth, I., Gonzalez, J.M., Laiz, L., and Saiz-Jimenez, C. 2005a. Agromyces salentinus sp. nov. and Agromyces neolithicus sp. nov. Int. J. Syst. Evol. Microbiol. 55, 153-157.

Jurado, V., Groth, I., Gonzalez, J.M., Laiz, L., Schuetze, B., and SaizJimenez, C. 2005b. Agromyces italicus sp. nov., Agromyces humatus sp. nov. and Agromyces lapidis sp. nov., isolated from Roman catacombs. Int. J. Syst. Evol. Microbiol. 55, 871-875.

Kanehisa, M., Sato, Y., and Morishima, K. 2016. BlastKOALA and GhostKOALA: KEGG tools for functional characterization of genome and metagenome sequences. J. Mol. Biol. 428, 726-731.

Kimura, M. 1980. A simple method for estimating evolutionary rates of base substitutions through comparative studies of nucleotide sequences. J. Mol. Evol. 16, 111-120.

Kumar, S., Stecher, G., and Tamura, K. 2016. MEGA7: molecular evolutionary genetics analysis version 7.0 for bigger datasets. Mol. Biol. Evol. 33, 1870-1874.

Lai, B., Plan, M.R., Averesch, N.J., Yu, S., Kracke, F., Lekieffre, N., Bydder, S., Hodson, M.P., Winter, G., and Krömer, J.O. 2017. Quantitative analysis of aromatics for synthetic biology using liquid chromatography. Biotechnol. J. 12, 1600269.

Li, J., Lu, S., Jin, D., Yang, J., Lai, X.H., Mi, F., Zhang, D., Zhang, G., Tian, Z., Dong, K., et al. 2020. Agromyces badenianii sp. nov., isolated from plateau pika (Ochotona curzoniae). Int. J. Syst. Evol. Microbiol. 70, 2247-2253.

Meier-Kolthoff, J.P., Auch, A.F., Klenk, H.P., and Göker, M. 2013. Genome sequence-based species delimitation with confidence intervals and improved distance functions. BMC Bioinformatics 14,60 .

Mitsukawa, Y., Hibi, M., Matsutani, N., Horinouchi, N., Takahashi, S., and Ogawa, J. 2018. New nucleoside hydrolase with transribosylation activity from Agromyces sp. MM-1 and its application for enzymatic synthesis of 2'-O-methylribonucleosides. $J$. Biosci. Bioeng. 125, 38-45.

Noda, S. and Kondo, A. 2017. Recent advances in microbial production of aromatic chemicals and derivatives. Trends Biotechnol. 35, 785-796.

Ortiz-Martinez, A., Gonzalez, J.M., Evtushenko, L.I., Jurado, V., Laiz, L., Groth, I., and Saiz-Jimenez, C. 2004. Reclassification of Agromyces fucosus subsp. hippuratus as Agromyces hippuratus sp. nov., comb. nov. and emended description of Agromyces fucosus. Int. J. Syst. Evol. Microbiol. 54, 1553-1556.

Park, E.J., Kim, M.S., Jung, M.J., Roh, S.W., Chang, H.W., Shin, K.S., and Bae, J.W. 2010. Agromyces atrinae sp. nov., isolated from fermented seafood. Int. J. Syst. Evol. Microbiol. 60, 1056-1059.

Parte, A.C. 2018. LPSN - List of prokaryotic names with standing in nomenclature (bacterio.net), 20 years on. Int. J. Syst. Evol. Microbiol. 68, 1825-1829.

Pierlé, S.A., Morales, C.O., Martínez, L.P., Ceballos, N.A., Rivero, J.J., Díaz, O.L., Brayton, K.A., and Setién, A.A. 2015. Novel waddlia intracellular bacterium in Artibeus intermedius fruit bats, Mexico. Emerg. Infect. Dis. 21, 2161-2163.

Price, M.N., Dehal, P.S., and Arkin, A.P. 2009. FastTree: computing large minimum evolution trees with profiles instead of a distance matrix. Mol. Biol. Evol. 26, 1641-1650.

Richter, M. and Rosselló-Móra, R. 2009. Shifting the genomic gold standard for the prokaryotic species definition. Proc. Natl. Acad. Sci. USA 106, 19126-19131.

Sridhar, S., Wang, A.Y., Chan, J.F., Yip, C.C., Lau, S.K., Woo, P.C., and Yuen, K.Y. 2015. First report of human infection by Agromyces mediolanus, a Gram-positive organism found in soil. J. Clin. Microbiol. 53, 3377-3379.

Wang, X., Yang, J., Lu, S., Lai, X.H., Jin, D., Pu, J., Zhang, G., Huang, Y., Zhu, W., Wu, X., et al. 2018. Nocardioides houyundeii sp. nov., isolated from Tibetan antelope faeces. Int. J. Syst. Evol. Microbiol. 68, 3874-3880.

Wayne, L.G. 1988. International committee on systematic bacteriology: announcement of the report of the ad hoc committee on reconciliation of approaches to bacterial systematics. Zentralbl. Bakteriol. Mikrobiol. Hyg. A 268, 433-434.

Wee, W.Y., Dutta, A., and Choo, S.W. 2017. Comparative genome analyses of mycobacteria give better insights into their evolution. PLOS ONE 12, e0172831.

Wyatt, A.W., Mo, F., Wang, Y., and Collins, C.C. 2013. The diverse heterogeneity of molecular alterations in prostate cancer identified through next-generation sequencing. Asian J. Androl. 15, 301-308.

Yasuhira, K., Tanaka, Y., Shibata, H., Kawashima, Y., Ohara, A., Kato, D., Takeo, M., and Negoro, S. 2007. 6-Aminohexanoate oligomer hydrolases from the alkalophilic bacteria Agromyces sp. strain KY5R and Kocuria sp. strain KY2. Appl. Environ. Microbiol. 73, 7099-7102.

Yoon, S.H., Ha, S.M., Kwon, S., Lim, J., Kim, Y., Seo, H., and Chun, J. 2017a. Introducing EzBioCloud: a taxonomically united database of $16 \mathrm{~S}$ rRNA gene sequences and whole-genome assemblies. Int. J. Syst. Evol. Microbiol. 67, 1613-1617.

Yoon, S.H., Ha, S.M., Lim, J., Kwon, S., and Chun, J. 2017b. A largescale evaluation of algorithms to calculate average nucleotide identity. Antonie van Leeuwenhoek 110, 1281-1286.

Yoon, J.H., Schumann, P., Kang, S.J., Park, S., and Oh, T.K. 2008. Agromyces terreus sp. nov., isolated from soil. Int. J. Syst. Evol. Microbiol. 58, 1308-1312.

Zgurskaya, H., Evtushenko, L., Akimov, V., Voyevoda, H., Dobrovolskaya, T., Lysak, L., and Kalakoutskii, L. 1992. Emended description of the genus Agromyces and description of Agromyces cerinus subsp. cerinus sp. nov., subsp. nov., Agromyces cerinus subsp. nitratus sp. nov., subsp. nov., Agromyces fucosus subsp. fucosus sp. nov., subsp. nov., and Agromyces fucosus subsp. hippuratus sp. nov., subsp. nov. Int. J. Syst. Evol. Microbiol. 42, 635-641.

Zhao, H.M., Du, H., Lin, J., Chen, X.B., Li, Y.W., Li, H., Cai, Q.Y., Mo, C.H., Qin, H.M., and Wong, M.H. 2016. Complete degradation of the endocrine disruptor di-(2-ethylhexyl) phthalate by a novel Agromyces sp. MT-O strain and its application to bioremediation of contaminated soil. Sci. Total Environ. 562, 170-178. 